\title{
Screening of potential inhibitors of COVID-19 with repurposing approach via molecular docking
}

\author{
Negin Alizadehmohajer ${ }^{1} \cdot$ Abtin Behmardi $^{2} \cdot$ Simin Najafgholian ${ }^{3} \cdot$ Shabnam Moradi $^{4} \cdot$ Forogh Mohammadi $^{5}$. \\ Reza Nedaeinia $^{6}$ (D) Shaghayegh Haghjooy Javanmard ${ }^{7}$. Ehsan Sohrabi ${ }^{8} \cdot$ Rasoul Salehi $^{6,9} \cdot$ Gordon A. Ferns $^{10}$. \\ Asieh Emami Nejad ${ }^{11} \cdot$ Mostafa Manian $^{12}$
}

Received: 24 November 2020 / Revised: 14 July 2021 / Accepted: 1 October 2021 / Published online: 4 February 2022

(c) The Author(s), under exclusive licence to Springer-Verlag GmbH Austria, part of Springer Nature 2021

\begin{abstract}
SARS-CoV-2 (COVID-19) is the causative organism for a pandemic disease with a high rate of infectivity and mortality. In this study, we aimed to assess the affinity between several available small molecule and proteins, including Abl kinase inhibitors, Janus kinase inhibitor, dipeptidyl peptidase 4 inhibitors, RNA-dependent RNA polymerase inhibitors, and Papainlike protease inhibitors, using binding simulation, to test whether they may be effective in inhibiting COVID-19 infection through several mechanisms. The efficiency of inhibitors was evaluated based on docking scores using AutoDock Vina software. Strong ligand-protein interactions were predicted among some of these drugs, that included: Imatinib, Remdesivir, and Telaprevir, and this may render these compounds promising candidates. Some candidate drugs might be efficient in disease control as potential inhibitors or lead compounds against the SARS-CoV-2. It is also worth highlighting the powerful immunomodulatory role of other drugs, such as Abivertinib that inhibits pro-inflammatory cytokine production associated with cytokine release syndrome (CRS) and the progression of COVID-19 infection. The potential role of other Abl kinase inhibitors, including Imatinib in reducing SARS-CoV and MERS-CoV viral titers, immune regulatory function and the development of acute respiratory distress syndrome (ARDS), indicate that this drug may be useful for COVID-19, as the SARS-CoV-2 genome is similar to SARS-CoV.
\end{abstract}

Keywords COVID-19 Abl kinase inhibitors · Janus kinase inhibitor · Dipeptidyl peptidase 4 inhibitors $\cdot$ RNA-dependent RNA polymerase inhibitors $\cdot$ Papain-like protease inhibitors

Asieh Emami Nejad

Emami_asieh@yahoo.com

$\triangle$ Mostafa Manian

Mostafamanian@gmail.com

1 Department of Medical Biotechnology and Translational Medicine, University of Milan, 20133 Milano, Italy

2 Cellular and Molecular Research Center, Research Institute for Prevention of Non-communicable, Qazvin University of Medical Sciences, Qazvin, Iran

3 Department of Emergency Medicine, School of Medicine, Arak University of Medical Sciences, Arak, Iran

4 Department of Basic Sciences, School of Veterinary Medicine, Shiraz University, Shiraz, Iran

5 Department of Veterinary, Agriculture Faculty, Kermanshah Branch, Islamic Azad University, Kermanshah, Iran

6 Pediatric Inherited Diseases Research Center, Research Institute for Primordial Prevention of Non-communicable Disease, Isfahan University of Medical Sciences, Isfahan, Iran
7 Applied Physiology Research Center, Isfahan University of Medical Sciences, Isfahan, Iran

8 Department of Medical Genetics and Molecular Biology, Faculty of Medicine, Iran University of Medical Sciences, Tehran, Iran

9 Department of Genetics and Molecular Biology, School of Medicine, Isfahan University of Medical Sciences, Isfahan, Iran

10 Division of Medical Education, Brighton and Sussex Medical School, Falmer, Brighton BN1 9PH, Sussex, UK

11 Department of Biology, Payame Noor University (PNU), P.O. Box 19395-3697, Tehran, Iran

12 Isfahan Neurosciences Research Center, Alzahra Research Institute, Isfahan University of Medical Sciences, Isfahan, Iran 


\begin{tabular}{|c|c|}
\hline \multicolumn{2}{|c|}{ Abbreviations } \\
\hline ARDS & Acute respiratory distress syndrome \\
\hline SARS-CoV & $\begin{array}{l}\text { Severe acute respiratory syndrome } \\
\text { coronavirus }\end{array}$ \\
\hline MERS-CoV & $\begin{array}{l}\text { Middle East respiratory syndrome } \\
\text { coronavirus }\end{array}$ \\
\hline ACE & Angiotensin-converting enzyme \\
\hline PDB & Protein Data Bank \\
\hline PDBQT & $\begin{array}{l}\text { Protein Data Bank, Partial Charge (Q), } \\
\text { and Atom Type (T) }\end{array}$ \\
\hline MVD & Molecular docking software \\
\hline CML & Chronic myelogenous leukemia \\
\hline ALL & Acute lymphocytic leukemia \\
\hline TKI & Tyrosine kinase inhibitor \\
\hline EGFR & Epidermal growth factor receptor \\
\hline BTK & Bruton's tyrosine kinase \\
\hline CRS & Cytokine release syndrome \\
\hline JAK inhibitor & Janus kinase inhibitor \\
\hline ACE2 & Angiotensin-converting enzyme 2 \\
\hline AT2R & Angiotensin II receptor \\
\hline DPP4i & Dipeptidyl peptidase 4 inhibitors \\
\hline RdRP & RNA-dependent RNA polymerase \\
\hline RDV & Remdesivir \\
\hline
\end{tabular}

\section{Introduction}

Coronaviruses are enveloped RNA viruses that include those causing severe acute respiratory syndrome coronavirus (SARS-CoV) and Middle East respiratory syndrome coronavirus (MERS-CoV) (Divya et al. 2020). SARS-CoV-2 is a newly emergent coronavirus that causes a respiratory illness and that has resulted in a global pandemic, having been first identified in Wuhan, China, in December 2019 (Sisk et al. 2018; WHO 2020). COVID-19 has two categories of proteins; structural proteins that include: Spike (S) that characterize all coronaviruses, Nucleocapsid (N), Matrix (M), and Envelope (E); and non-structural proteins, that include: proteases (nsp3 and nsp5) and RdRp (nsp12) (Divya et al. 2020; Ibrahim et al. 2020). An essential step for replication of the enveloped viruses such as coronaviruses is their entry into the host cells by fusing with cell membranes (Prompetchara et al. 2020). The virus attaches and enters the host cells in the respiratory tract using the spike protein (Ibrahim et al. 2020). It has also been shown that SARS-CoV-2 can infect $\mathrm{T}$ cells through a receptor-dependent, $\mathrm{S}$ protein-mediated membrane fusion (Wang et al. 2020a). COVID-19 infection may be associated with lymphopenia and occasionally the release of very high levels of inflammatory cytokines that has been described as a "cytokine storm." The latter has a major role in the development of inflammation-induced lung injury, that can lead to acute respiratory distress syndrome (ARDS), respiratory failure, and death (Prompetc.hara et al.
2020; Chen et al. 2020). Symptoms of COVID-19 include: dry cough, fever, breathing difficulties, headache, pneumonia (Zhou et al. 2020), new loss of taste or smell, nausea or vomiting and diarrhea (DeBiasi et al. 2020). An increased total neutrophil count and decreased total lymphocytes are related to disease severity and risk of mortality (Sun et al. 2020). There is currently no specific medication for COVID19 , so neutralizing monoclonal antibody-based therapeutics and small-molecules are being evaluated to treat COVID-19 (Choudhary et al. 2020). There are three key drug-targeting strategies for SARS-CoV-2:

1. Blocking the entry of the virus into the host cells.

2. Host's undirected inflammatory response reduction.

3. Block replication within the host (Jakovac 2020; Quartuccio et al. 2020).

Moreover, there are many factors that might contribute to viral infection through different mechanisms of action directly or indirectly, including Abl kinase, Janus kinase, dipeptidyl peptidase 4, RNA-dependent RNA polymerase, viral main protease and Papain-like protease, which will be discussed further. Repurposing FDA-approved drugs create opportunities to develop new treatments for COVID-19, especially for patients who are suffering from severe disease; for example, there is the possibility that some drugs such as Imatinib can be repurposed (Shaw et al. 2019). Other drugs are being evaluated in clinical trials, such as Abelson (Abl) kinase inhibitors (Imatinib), anti-malarials, RNA-dependent RNA polymerase (RdRP) inhibitors, and Papain-like protease inhibitors. The ClinicalTrials.gov Web site describes the candidate drugs currently being tested for COVID-19 prevention and/or treatment (Table 1). In silico evaluation of the possible viral inhibitory effectiveness of small molecules can be assessed by ligand-binding simulations. Therefore, the aim of this study was to evaluate the efficiency of candidate drugs and binding affinity with structural component of SARS-CoV-2, particularly in the contest of small-molecule inhibitors; Abl kinase inhibitors (Imatinib), Janus kinase inhibitor, dipeptidyl peptidase 4 inhibitors, RdRP inhibitors, and Papain-like protease inhibitors using in silico simulations by AutoDock Vina software.

\section{Methods}

\subsection{Protein preparation}

For molecular docking, SARS-CoV-2 spike protein (PDB: 6XR8), SARS-CoV spike protein (PDB: 5X58), SARS-CoV-2 main protease (PDB:6LU7), RNA-dependent RNA polymerases (RdRps) (PDB: 6M71), and papain-like protease (PLpro) (PDB: 6W9C) were chosen to be the target proteins which 
Table 1 Clinical trials related to the coronavirus disease 2019-nCoV and candidate drugs

\begin{tabular}{|c|c|c|c|c|c|}
\hline $\begin{array}{l}\text { ClinicalTrials. } \\
\text { gov identifier }\end{array}$ & Drug class & Drug name & Estimated enrollment & Aim & Primary purpose \\
\hline NCT04357613 & Abl kinase inhibitor & Imatinib & 99 participants & $\begin{array}{l}\text { Test the value of Imatinib } \\
\text { as an early treatment of } \\
\text { COVID-19 }\end{array}$ & Treatment \\
\hline NCT04330300 & $\begin{array}{l}\text { ACE inhibitor, angiotensin } \\
\text { receptor blocker }\end{array}$ & $\begin{array}{l}\text { Benazepril, Captopril, } \\
\text { Enalapril, Fosinopril, } \\
\text { Lisinopril, Perindopril, } \\
\text { Quinapril, Ramipril, } \\
\text { Trandolapril }\end{array}$ & 2414 participants & $\begin{array}{l}\text { Coronavirus angioten- } \\
\text { sin-converting enzyme } \\
\text { inhibitors, angiotensin } \\
\text { receptor blockers inves- } \\
\text { tigation }\end{array}$ & Prevention \\
\hline NCT04280705 & RdRps inhibitor & Remdesivir & 1062 participants & $\begin{array}{l}\text { Evaluate the efficacy and } \\
\text { safety of Remdesivir } \\
\text { (Phase 3) }\end{array}$ & Treatment \\
\hline NCT04276688 & $\begin{array}{l}\text { RdRps inhibitor, 3CLpro } \\
\text { inhibitor }\end{array}$ & $\begin{array}{l}\text { Ribavirin, Lopinavir, } \\
\text { Ritonavir }\end{array}$ & 127 participants & $\begin{array}{l}\text { Investigate a combination } \\
\text { of Lopinavir, Ritonavir, } \\
\text { Ribavirin and interferon } \\
\text { beta-1b }\end{array}$ & Treatment \\
\hline NCT04310228 & $\begin{array}{l}\text { RdRps inhibitor, interleu- } \\
\text { kin-6 (IL-6) blockers }\end{array}$ & Favipiravir, Tocilizumab & 150 participants & $\begin{array}{l}\text { Evaluate the efficacy and } \\
\text { safety of Favipiravir } \\
\text { combined with Tocili- } \\
\text { zumab }\end{array}$ & Treatment \\
\hline NCT04307693 & 3CL protease inhibitor & Lopinavir, Ritonavir & 65 participants & $\begin{array}{l}\text { Investigate Lopinavir, } \\
\text { Ritonavir in patients with } \\
\text { mild coronavirus disease }\end{array}$ & Treatment \\
\hline NCT04440007 & $\begin{array}{l}\text { EGFR tyrosine kinase } \\
\text { inhibitor and BTK } \\
\text { inhibitor }\end{array}$ & Abivertinib & 80 participants & $\begin{array}{l}\text { A phase } 2 \text { randomized } \\
\text { study of the efficacy and } \\
\text { safety of Abivertinib } \\
\text { maleate in hospitalized } \\
\text { patients with COVID-19 }\end{array}$ & Treatment \\
\hline NCT04321993 & Janus kinase inhibitor & Baricitinib & 800 participants & $\begin{array}{l}\text { Treatment of moderate- } \\
\text { to-severe coronavirus } \\
\text { disease in hospitalized } \\
\text { patients }\end{array}$ & Treatment \\
\hline NCT04365517 & $\begin{array}{l}\text { Dipeptidyl peptidase } 4 \\
\text { inhibitor }\end{array}$ & Sitagliptin & 170 participants & $\begin{array}{l}\text { The effect of Sitagliptin } \\
\text { treatment in COVID-19- } \\
\text { positive diabetic patients }\end{array}$ & Treatment \\
\hline NCT04377620 & $\begin{array}{l}\text { Janus-associated kinase } \\
\text { (JAK) inhibitor }\end{array}$ & Ruxolitinib & 500 participants & $\begin{array}{l}\text { Assess the efficacy and } \\
\text { safety of Ruxolitinib } \\
\text { in participants with } \\
\text { COVID-19-associated } \\
\text { ARDS }\end{array}$ & Treatment \\
\hline NCT03891420 & $\begin{array}{l}\text { Viral RNA polymerase } \\
\text { inhibitor }\end{array}$ & Galidesivir & 132 participants & $\begin{array}{l}\text { Evaluate the safety, phar- } \\
\text { macokinetics, and antivi- } \\
\text { ral effects of Galidesivir }\end{array}$ & Treatment \\
\hline
\end{tabular}

were obtained from the RCSB (http://www.rscb.org) Protein Data Bank in PDB format. Due to the high number of reported structures, in the present study, we used the structures, which had been previously studied in similar bioinformatics studies.

\subsection{Ligand preparation}

Based on literature reviews, we tested 3D structures of the drugs, including: Imatinib (Abl kinase inhibitor), Ruxolitinib and Baricitinib (JAK inhibitors), Sitagliptin (dipeptidyl peptidase 4 inhibitors), Remdesivir, Ivermectin, Galidesivir,
Ribavirin, Favipiravir (RdRps inhibitors), Telaprevir, Boceprevir, Grazoprevir (protease inhibitors) using Drug bank (https://www.drugbank.ca/) in Structure-data file (PDB) format. They also were converted into (PDBQT) by AutoDock Tools software. The PDBQT format is similar to PDB. However, it includes partial charges that are required for docking.

\subsection{Docking analysis}

To simulate protein and ligand-binding affinity, molecular docking softwares (MVD) including AutoDock Tools 
(version 1.5.6) (http://autodock.scripps.edu) and AutoDock Vina (http://autodock.scripps.edu) were used (Trott and Olson 2010; Tools 2016). After that, the downloaded proteins were inserted to the work place to be prepared. First, the water molecules were deleted, and then, polar Hydrogen and Kollman charges were added by the software tools. Then, Autogrid determined the native ligand position on the binding site by arranging the grid coordinates $(X, Y$, and $Z$ ). After the preparations, the bioactive conformations were simulated by AutoDock Vina. The exhaustiveness parameter that controls the extent of the search was chosen as 8 , and 9 models were generated for each ligand. According to the received results, lower energy scores demonstrate the best protein-ligand interactions. Models with binding energy lower than $6 \mathrm{kcal} / \mathrm{mol}$ can be considered. Therefore, the lowest binding energy value of $10 \mathrm{kcal} / \mathrm{mol}$ as a threshold to define a physical drug-target interaction was used. Different poses of the ligands affect the estimation of the docking score, so the most active forms were used to obtain an accurate estimation. RMSD values of three or more indicate that no docking has occurred. Only one docking position with the root-mean-square deviations of atomic positions $(\mathrm{RMSD}=0)$ is highly valid and reported. The interactions of amino acids and ligands were also examined using Discovery Studio 4.5.

\subsection{Clinical trials}

Clinical trials data were downloaded from clinicaltrials.gov on 4 April 2020. Small molecule drugs used to prevent or treat COVID-19 were selected in interventional category (Table 1).

\section{Results and discussion}

In the present study, based on the importance of inhibition in reducing or stopping the activity of COVID-19, ligand with the ability to inhibit the virus in the drug database has been used. For this purpose, and considering the importance of identifying ligand-receptor interactions, the effectiveness of each of these ligands on the related proteins has been evaluated during the molecular docking simulation process.

\subsection{Abl kinase inhibitors}

Abl kinases are non-receptor tyrosine kinases that are involved in various cellular processes, especially as mediators of viral infection and/or may be involved in T-cell signaling (Khatri et al. 2016). Imatinib is an Abl kinase inhibitor used to treat Philadelphia chromosome-positive chronic myelogenous leukemia (CML) and acute lymphocytic leukemia (ALL). This small-molecule inhibitor works by inhibiting $B c r-A b l$ tyrosine kinase (Kerkelä et al. 2006). It has been shown, from previous studies, that an Abelson (Abl) kinase inhibitor, Imatinib, reduces SARS-CoV and MERS-CoV viral titers. In the same study, they also investigated the bronchitis virus (IBV) to study the function of Abl kinase activity during coronavirus infection and found that Imatinib and two different Abl kinase inhibitors, GNF2 and GNF5, reduced IBV titers by blocking virus infection (Sisk et al. 2018). Previously, Imatinib was shown to block the entry of SARS-CoV or MERS-CoV S protein (Sisk et al. 2018). SARS-CoV-2 is highly homologous to SARS-CoV, so studying the effects of Abl kinase inhibitors on IBV, SARS$\mathrm{CoV}$ and MERS-CoV may be useful in identifying the host cell pathways required for COVID-19 infection. It may also provide insights into potential strategies for the treatment of COVID-19 especially using Imatinib. Virus-cell and cell-cell fusion induced by the coronavirus $\mathrm{S}$ protein has a very similar mechanism. Abl kinase activity plays a role in cytoskeletal rearrangement, regulating endothelial barrier, and junctional dynamics, and hence Abl kinase inhibitors might also be capable of interacting by interfering with the actin dynamics needed for virus-cell and cell-cell fusion in SARA-CoV-2. Furthermore, studies have indicated that Abl kinase regulates inflammatory signaling, NFKB signaling, and oxidant-induced epithelial cells injury caused by infection and ARDS which can be followed by COVID-19 (Sisk et al. 2018; Rizzo et al. 2015). In epithelial cell injury, $\mathrm{H}_{2} \mathrm{O}_{2}$ release leads to $\mathrm{C}-\mathrm{Abl}$ activation and nuclear translocation. $\mathrm{C}-\mathrm{Abl}$ inhibition by Imatinib increases the expression of antioxidant proteins such as catalase and glutathione peroxidase, which have been reduced due to oxidative stress. Therefore, treatment with Imatinib during ARDS may prevent the death of lung cells (Rizzo et al. 2015). Coleman et al. investigated the Abl kinase inhibitors, including Imatinib, in SARS-CoV and MERS-CoV in vitro. In the early stages of infection, after internalization and endosomal trafficking, the anti-CoV activity of Imatinib is affected by inhibiting virion fusion in the endosomal membrane. Imatinib inhibits a step-in virion replication before the genomic production of RNA. They also investigated the role of $\mathrm{Abl}_{2}$ in the replication of SARS-CoV and MERS-CoV. To knock down the $\mathrm{Abl}_{2}$ protein levels, siRNA was used. They demonstrated that $\mathrm{Abl}_{2}$ expression is essential for a productive viral replication and can be blocked by Imatinib (Coleman et al. 2016). Imatinib and its methane sulfonate derivative can be used in treating viral liver diseases, in particular viral hepatitis by inhibiting replication, transmission, or both, of hepatitis viruses or of other RNA viruses including respiratory syncytial virus, herpes virus, influenza virus, poxvirus, para influenza virus, rhinovirus, yellow fever virus, West Nile virus, and encephalitis virus to maintain or decrease RNA viral load. Although it is not meant to be limited to any particular mechanism of action or bound by definition, it is suspected that Imatinib's 
antiviral properties may be partly due to its ability to inhibit viral replication and transmission. Cellular signal transduction pathways are known to play an important role in viral infection, and cellular phosphorylation events during viral infection so they are required to effectively replicate and proliferate the virus. Several cellular signaling pathways, related to viral replication, have been investigated. Tyrosine kinase inhibitors can be used, for example, epidermal receptor growth factor (EGFR) inhibitors such as monoclonal antibodies and small-molecule inhibitors. EGFR inhibitors including monoclonal antibodies, such as IMC-C225 (Cetuximab), Trastuzumab (Herceptin), and others (ABXEGF, EMD 72000), and tyrosine kinase inhibitors, such as OSI-774 (Erlotinib, Tarceva), ZD1839 (Gefitinib, Iressa), and others (GW2016, CI-1033), can be used in combination therapy with Imatinib. Monoclonal antibodies can block extracellular ligand binding, but at the intracellular portion of the receptor, the small-molecule inhibitors may exert their effects to prevent tyrosine kinase phosphorylation and the activation of signal transduction pathways (Riviere et al. 2012). Consequently, combination therapy may be useful in COVID-19 treatment, similar to other RNA viruses. According to the Hubei Anti-Cancer Association Chronic Myeloid Leukemia Standardized Management Collaboration Group research on 299 CML patients who responded optimally to anti-CML therapy using Imatinib and other tyrosine kinase inhibitors, $0.3 \%$ of patients were infected by SARS-CoV-2 and among those who failed to respond to CML treatment, $2 \%$ of patients were diagnosed with COVID-19. Therefore, patients who failed to receive an appropriate response to anti-CML therapy medications were more likely to get infected by SARS-CoV-2. Although more detailed clinical data and studies on the prevalence of COVID-19 in patients with CML is required, this idea may be consistent with several possibilities (Wang et al. 2020). For instance, it has been shown that the total number of natural killer (NK) cells and
Regulatory T cells was decreased markedly in patients with CML as well as COVID-19 infection (Zheng et al. 2020; Qin et al. 2020) while tyrosine kinase inhibitors are able to regulate the immune system by increasing the number of natural killer cells (NK) and Regulatory T cells (Wang et al. 2020). To assess the potential effectiveness of Imatinib on COVID-19, using molecular docking, we investigated the affinity and efficiency of Imatinib and possible intermediary proteins: Spike protein and RNA-dependent RNA polymerases (RdRps). According to the NCBI database and using the Basic Local Alignment Search Tool (BLAST), we found that SARS-CoV-2 spike protein (PDB: 6XR8) and SARSCoV spike protein (PDB: 5X58) Query Cover is $76.16 \%$ with a GMQE of 0.80 , which indicates that it is reasonable to consider these proteins similar. The docking results are shown in Table 2; low energy indicates the optimum protein-ligand complexes. Accordingly, docking scores for SARS-CoV-2 and SARS-CoV were -9.6 and $-10 \mathrm{kcal} / \mathrm{mol}$, respectively, which are low enough to show the appropriate protein-ligand complexes. Docking interactions of Imatinib based on docking studies are shown in Fig. 1. Furthermore, the type of interaction with the number of active site amino acids is also considered effective. In terms of interactions, the presence of hydrogen bond interactions can be very important as they have critical contributions to the binding structures and binding free energies, although the van der Waals and Pi-interactions contributed to the stabilization of the binding structures. If these interactions take place in the active position of proteins, it will be much better and more desirable. The interaction types and amino acids involved in the inhibition of proteins are shown in Table 6.

Binding interactions of Imatinib and SARS-CoV-2 spike protein shows that Imatinib interacts by forming hydrogen bonds with residue SER B: 50 and SER B: 967. A Pi-sigma interaction is also visible between the drug and amino acid THR B: 302 and Pi-Alkyl interactions with LEU C: 754
Table 2 The docking score of Imatinib to SARS-CoV-2 and SARS-CoV spike protein, SARS-CoV-2 RNA-dependent RNA polymerases (RdRps) (RMSD: 0.00)

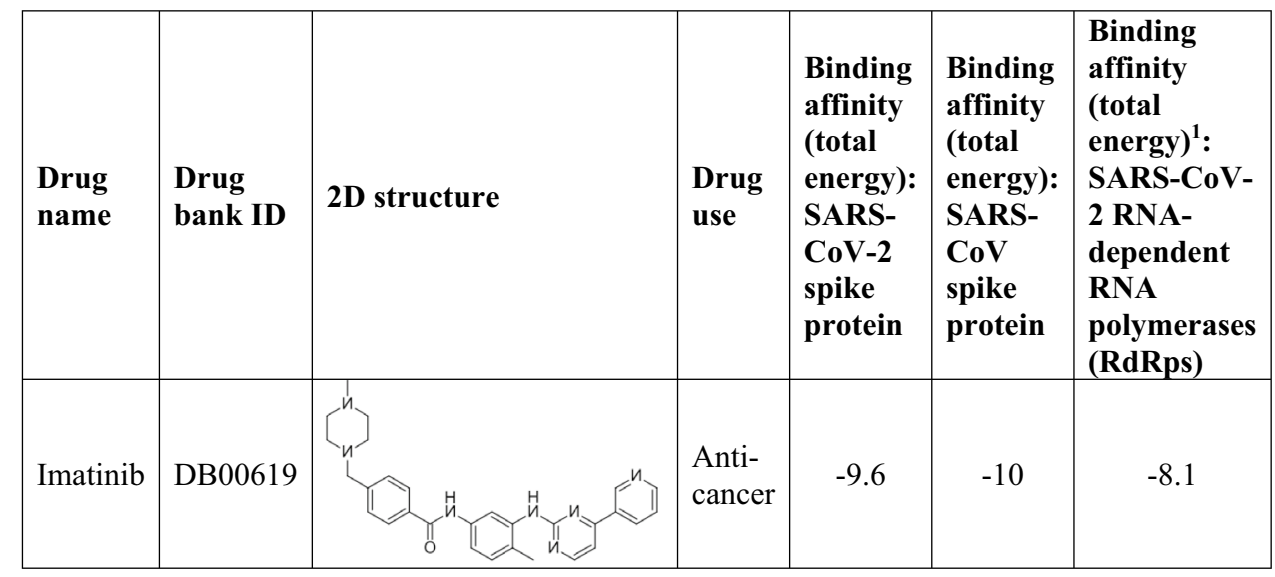

${ }^{1} \mathrm{Kcal} / \mathrm{mol}$ 


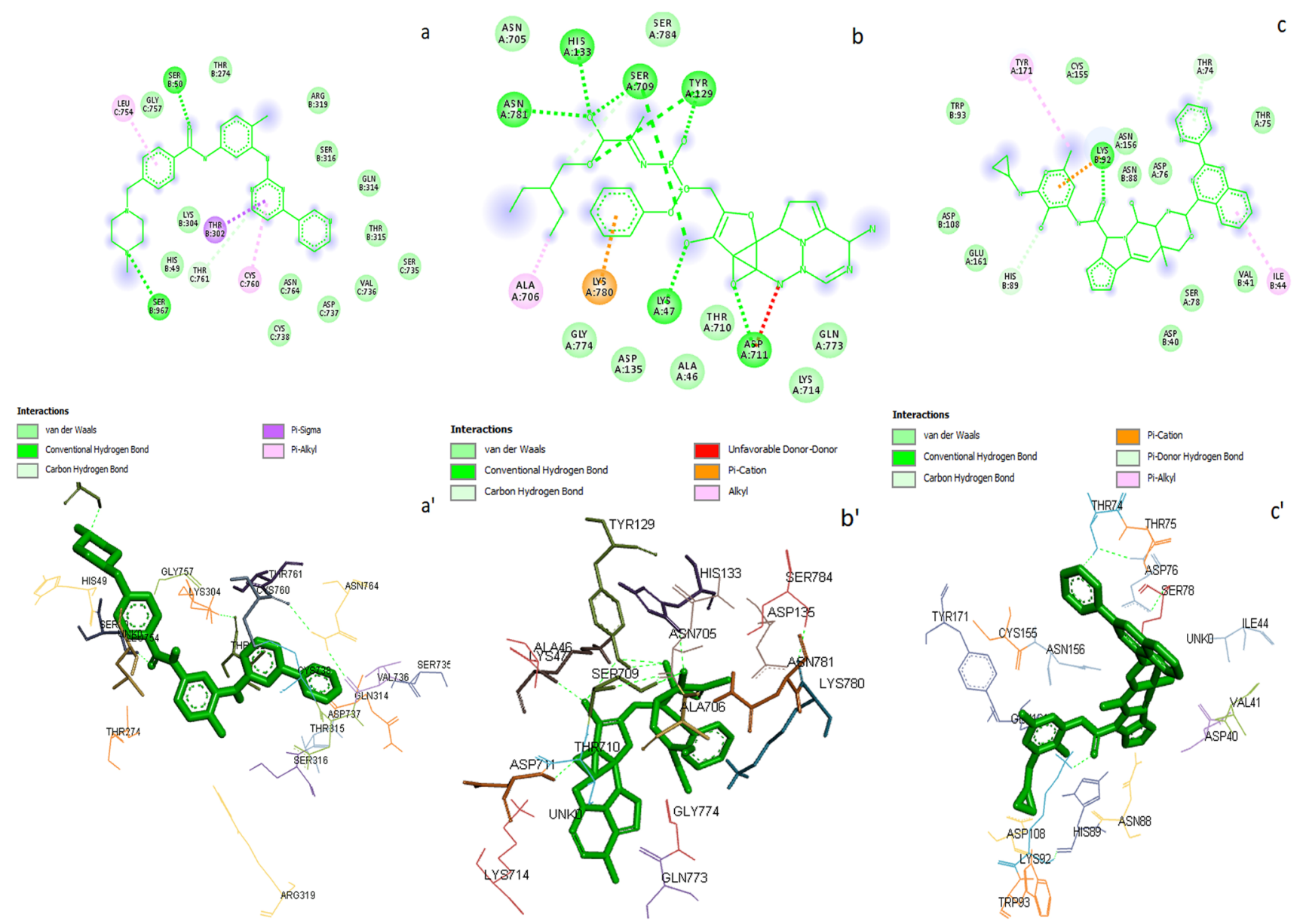

Fig. 1 Visualization of docked poses of top three drug candidates with their protein target. a Binding interactions of Imatinib with active site residues of SARS-CoV-2 spike protein. $\mathbf{a}^{\prime} 3 \mathrm{D}$ view of Imatinib with surrounding amino acids of 6 XR8. b Binding interac-

and CYS C: 760. The large number of Pi-sigma interactions which involves charge transfer and helps in intercalating the drug in the binding site of the receptor. Pi-Alkyl bond also improves the hydrophobic interactions of the ligand in the binding pocket of the receptor. With regards to the van der Waals interactions, it should be mentioned that there are 13 amino acids contributing to the ligand binding, including: LYS B: 304, HIS B: 49, ASN C: 764, CYS C: 738, ASP C: 737, VAL C: 736, SER C: 735, THR B: 315, GLN B: 314, SER B: 316, ARG B: 319, THR B: 274, and GLY C: 757. Imatinib inhibits SARS-CoV-2 with an IC50 of $130 \mathrm{nM}$. But, although imatinib binds to the receptor-binding domain (RBD) of SARS-CoV-2 spike protein, it does not inhibit the spike RBD:ACE2 interaction, suggesting a Bcr-Abl kinasemediated fusion inhibition mechanism is responsible for the inhibitory action (Mulgaonkar et al. 2020). Abivertinib is another small-molecule tyrosine kinase inhibitor (TKI) that is used in lung cancer treatment, targeting both mutant forms of the epidermal growth factor receptor (EGFR) and tions of Remdesivir with active site residues of RdRP. $\mathbf{b}^{\prime}$ 3D view of Remdesivir with surrounding amino acids of $6 \mathrm{M} 71$. $\mathbf{c}$ Binding interactions of Telaprevir with active site residues of PLpro. $\mathbf{c}^{\prime}$ 3D view of Telaprevir with surrounding amino acids of 6W9C

Bruton's tyrosine kinase (BTK). Abivertinib binds to the BTK receptor which results in receptor phosphorylation prevention. It also plays a powerful immunomodulatory role in vitro by inhibiting pro-inflammatory cytokine production that are associated with cytokine release syndrome (CRS) or cytokine storm and progression of COVID-19 infection such as IL-1beta, IL-6 and TNF-alpha in patients with acute respiratory distress syndrome (ARDS). It is worth noting that FDA clears Abivertinib for Phase 2 safety and efficacy study in hospitalized patients with moderate-to-severe COVID-19 (http://www.aceatherapeutics.com). This strongly indicates that the Abl kinase signaling pathway is a promising area to study for the development of antiviral therapies.

\subsection{Janus kinase inhibitor (JAK inhibitor)}

Janus kinase inhibitors are being used in the treatment of cancer and inflammatory diseases by inhibiting the activity of the Janus kinase family of enzymes (JAK1, JAK2, 
Table 3 The docking score of candidate inhibitors to SARS-CoV-2 main protease and SARS-CoV-2 spike protein (RMSD: 0.00)

\begin{tabular}{|c|c|c|c|c|c|}
\hline Drug name & Drug bank ID & 2D structure & $\begin{array}{c}\text { Protein } \\
\text { target }\end{array}$ & Drug use & $\begin{array}{l}\text { Binding } \\
\text { affinity } \\
\text { (total } \\
\text { energy) }^{1}\end{array}$ \\
\hline Ruxolitinib & DB08877 & & $\begin{array}{c}\text { SARS-CoV-2 } \\
\text { main } \\
\text { protease }\end{array}$ & $\begin{array}{l}\text { treatment of } \\
\text { intermediate } \\
\text { or high-risk } \\
\text { myelofibrosis }\end{array}$ & -6.2 \\
\hline baricitinib & DB11817 & & $\begin{array}{c}\text { SARS-CoV-2 } \\
\text { main } \\
\text { protease }\end{array}$ & $\begin{array}{l}\text { treatment of } \\
\text { rheumatoid } \\
\text { arthritis (RA) }\end{array}$ & -6.1 \\
\hline Sitagliptin & DB01261 & & $\begin{array}{l}\text { SARS-CoV-2 } \\
\text { spike } \\
\text { protein }\end{array}$ & $\begin{array}{c}\text { Treatment of } \\
\text { diabetes } \\
\text { mellitus type } 2\end{array}$ & -6.0 \\
\hline
\end{tabular}

${ }^{1} \mathrm{Kcal} / \mathrm{mol}$
JAK3, and TYK2), by interfering with the JAK-STAT signaling pathway (Pesu et al. 2008). Ruxolitinib is one of those inhibitors with an anti-inflammatory effect related to the inhibition of the release of cytokines. This drug is used for the treatment of myelofibrosis and polycythemia vera (PCV) (Mesa et al. 2012). Ruxolitinib has been approved in COVID-19 patients with respiratory failure with no invasive assisted ventilation required (Lorenzo et al. 2020). Improvement in chest computed tomography and faster recovery from lymphopenia were seen in patients as well (Cao et al. 2020). Another JAK inhibitor is Baricitinib used for rheumatoid arthritis. A randomized phase 2 trial for this drug has been licensed to the usual treatment of pneumonia in COVID-19 patients (Lorenzo et al. 2020). Transcription by interferon-activated JAK-STAT signaling pathway (mainly mediated by JAK1 and JAK2) contributes to the upregulation of several interferoncontrolled genes which destroy viruses in infected cells rapidly. Many viruses have formed strategies to combat interferon effects by blocking their signaling pathways, and viral-encoded factors that antagonize the JAK-STAT pathway are important virulence determinants. Therefore, the blocking of the JAK-STAT signal by Baricitinib results in interferon-mediated antiviral response inhibition that has an impact on SARS-CoV-2 infection progression (Favalli et al. 2020). According to another cohort study, Baricitinib in combination with Remdesivir and Hydroxychloroquine showed clinical improvement in patients (Titanji et al. 2020). Moreover, docking results between SARS-CoV-2 main protease and our two JAK inhibitors
(Ruxolitinib and Baricitinib) were -6.2 and $-6.1 \mathrm{kcal} /$ mol, respectively (Table 3 ).

\subsection{Dipeptidyl peptidase 4 inhibitors (DPP4i)}

Besides the main viral entrance port, angiotensin-converting enzyme 2 (ACE2), dipeptidyl peptidase 4 (DPP4) can be investigated as well. DPP4 is a type II transmembrane glycoprotein with its major role in glucose and insulin metabolism which is expressed in many tissues, such as the immune cells. In addition, it plays a significant role in immune regulation by activating $\mathrm{T}$ cells, modulating NF-jB pathway, and the expression of CD86. Dipeptidyl peptidase 4 inhibitors mainly sitagliptin can be used to treat diabetes mellitus type 2. Moreover, it was identified as a functional receptor for the MERS-CoV spike protein and although SARS-CoV-2 spike protein does not necessarily need DPP4. In spite of Sitagliptin and SARS-CoV-2 spike protein docking result with the score of $-6.0 \mathrm{kcal} / \mathrm{mol}$ and the possibility that it does not alter ACE2, the potential anti-inflammatory involvement of DPP4 inhibitors raises concerns about DPP4 modulation that might decrease the cytokine-mediated acute respiratory complications of COVID-19 infection (Lorenzo et al. 2020; Pal and Bhadada 2020) (Table 3).

\subsection{RNA-dependent RNA polymerase inhibitors}

RNA-dependent RNA polymerase (RdRP) is an enzyme that catalyzes the replication of RNA from an RNA template which is encoded in the genomes of all RNA viruses 
(Koonin et al. 1989) including SARS-CoV-2. There are some drugs that are considered to be nucleotide analog inhibitors of RdRps. Remdesivir (RDV) is one of those investigational drugs that have a wide variety of antiviral activities against RNA viruses including coronaviruses (Gordon et al. 2020). Remdesivir suppresses viral replication and it was initially tested in clinical trials to prevent the 2014 Ebola outbreak. Later investigations indicated Remdesivir's ability to inhibit replication of coronavirus, including SARS-CoV-2 as well (Eastman et al. 2020). In another cohort study, medical progress was observed in $68 \%$ of patients taken to the hospital with severe COVID-19 treated with Remdesivir (Grein et al. 2020). Ivermectin is another medication that we investigated via molecular docking. It is used to treat many types of parasite infestations, but recently, the antiviral effects against several SARS-CoV-2 have been identified. Ivermectin may inhibit the replication of SARS-CoV-2 in monkey with an IC50 of 2.2-2.8 $\mu \mathrm{M}$, which makes it a possible candidate for drug repurposing research. In addition, it is an in vitro inhibitor of SARS-CoV-2 replication via Importin $\alpha / \beta 1$ function (Caly et al. 2020; Yavuz and Ünal 2020). According to our docking result, it showed high affinity value of
- 8.8 kcal/mol with RdRP. In Japan, Favipiravir, an antiviral drug that targets the influenza viral RNA-dependent RNA polymerase, has been used against SARS-CoV-2 (Chen et al. 2020). Ribavirin and Galidesivir (Ibrahim et al. 2020) are other recommended drugs that we studied using AutoDock Vina. Accordingly, Remdesivir (Fig. 1) has the best binding capability with the score of $-9.0 \mathrm{kcal} / \mathrm{mol}$. From our docking studies, with the better binding energy compounds, the identified active residues were Lys47, Ser784, Ser709, Tyr129, His133, and Thr141. The major interaction between Remdesivir and RdRP is characterized by hydrogen bonding between the oxygen with TYR A: 129. A Pi-Cation interaction of aromatic ring and LYS A: 780 and an Alkyl interaction with ALA A: 706 have been observed. The docked result of the shown in Fig. 1 indicates the drug has eight hydrogen bond interactions with six amino acids shown in Table 6. Other important interactions such as alkyl, Pi-Cation interactions were also reported Table 6. Remdesivir high affinity has also been correlated with the existence of van der Waals forces formed on the amide substituents backbone with the respective amino acids GLY A: 774, ASP A:135, ALA A: 46, THR A: 710, LYS A: 714, GLN A: 773, ASN
Table 4 The docking score of candidate inhibitors to SARSCoV-2 RNA-dependent RNA polymerases (RdRps) (RMSD: 0.00 )

\begin{tabular}{|c|c|c|c|c|}
\hline Drug name & $\begin{array}{c}\text { Drug bank } \\
\text { ID }\end{array}$ & 2D structure & Drug use & $\begin{array}{c}\text { Binding } \\
\text { affinity } \\
\text { (total } \\
\text { energy) }\end{array}$ \\
\hline Remdesivir & DB14761 & & Antiviral & -9.0 \\
\hline Ivermectin & DB00602 & $B_{1 a}$ & $\begin{array}{c}\text { anti- } \\
\text { parasite }\end{array}$ & -8.8 \\
\hline Galidesivir & DB11676 & & Antiviral & -6.9 \\
\hline Ribavirin & DB00811 & & Antiviral & -6.3 \\
\hline Favipiravir & DB12466 & & Antiviral & -5.4 \\
\hline
\end{tabular}

${ }^{1} \mathrm{Kcal} / \mathrm{mol}$ 
Table 5 The docking score of candidate $\mathrm{HCV}$ protease inhibitors to SARS-CoV-2 Papain-like protease (PLpro) (RMSD: 0.00)

\begin{tabular}{|c|c|c|c|c|}
\hline Drug name & $\begin{array}{l}\text { Drug bank } \\
\text { ID }\end{array}$ & 2D structure & Drug use & $\begin{array}{r}\text { Binding affinity } \\
\text { (total energy) }\end{array}$ \\
\hline Telaprevir & DB05521 & & Anti-Hepatitis C & -9.9 \\
\hline Grazoprevir & DB11575 & & Anti-Hepatitis C & -8.7 \\
\hline Boceprevir & DB08873 & & Anti-Hepatitis C & -7.8 \\
\hline
\end{tabular}

${ }^{1} \mathrm{Kcal} / \mathrm{mol}$

Table 6 Interaction types and amino acids involved in the inhibition of PDB: 6XR8, PDB: 6M71 and PDB: 6W9C with the top three drug candidates

\begin{tabular}{|c|c|c|c|c|c|c|}
\hline Ligand & Protein & $\begin{array}{l}\text { Conventional } \\
\text { hydrogen bond }\end{array}$ & Carbon hydrogen bond & $\begin{array}{l}\text { Pi-sigma and } \\
\text { amide interaction }\end{array}$ & Alkyl interaction & $\mathrm{Pi}-$ cation interaction \\
\hline Imatinib & PDB: 6XR8 & $\begin{array}{l}\text { SER B:50 } \\
\text { SER B: } 967\end{array}$ & THR C: 761 & THR B: 302 & $\begin{array}{l}\text { CYS C: } 760 \\
\text { LEU C: } 754\end{array}$ & - \\
\hline Remdesivir & PDB: 6M71 & $\begin{array}{l}\text { ASN A: } 781 \\
\text { HIS A: } 133 \\
\text { SER A: } 709 \\
\text { TYR A: } 129 \\
\text { LYS A: } 47 \\
\text { ASP A: } 711\end{array}$ & SER A: 709 & - & ALA A: 706 & LYS A: 780 \\
\hline Telaprevir & PDB: 6W9C & LYS B: 92 & $\begin{array}{l}\text { HIS B: } 89 \\
\text { THR A: } 74\end{array}$ & - & $\begin{array}{l}\text { ILE B: } 44 \\
\text { TYR A: } 171\end{array}$ & LYS B: 92 \\
\hline
\end{tabular}

A: 705, and SER A: 784, which established a strong cohesive environment, thus, stabilizing the formed complex. It exhibits effective in vitro activity against SARS-CoV-2 with an $\mathrm{EC}_{50}$ at $48 \mathrm{~h}$ of $0.77 \mu \mathrm{M}$ in Vero E6 cells (Wang et al. 2020a). On the other hand, Favipiravir had the least affinity to RdRps despite the recorded efficiency based on clinical trials (Table 4).

\subsection{Papain-like protease inhibitors}

Papain-like protease (PLpro) is characterized in different coronaviruses, including SARS and MERS (Elfiky and Ibrahim 2020). The genome of SARS-CoV-2 encodes for different proteins including PLpro (Durdagi et al. 2020). The SARS-CoV PLpro and SARS-CoV-2 PLpro protein sequences are similar, so protease inhibitors that have shown efficacy against SARS-CoV might be similarly effective against SARS-CoV-2. Papain-like protease (PLpro) has a crucial role in the viral life cycle (Arya et al. 2020; Talluri 2020). Targeting PLpro with antiviral drugs may result in viral replication blockage and the deregulation of signaling cascades in infected cells inhibition (Claudio and Juan 2020). Consequently, anti-HCV drugs (Telaprevir, Grazoprevir, and Boceprevir) that bind to the SARS-CoV-2 PLpro active site (contained residues Asp164, Val165, Arg166, Glu167, Met 208, Ala246, Pro247, Pro248, Tyr 264, Gly266, Asn267, Tyr 268, Gln269, Cys217, Gly271, Tyr273, Thr301 and Asp302), may, therefore, oppose viral replication (Elfiky and Ibrahim 2020; Arya et al. 2020). Similarly, our study showed that Telaprevir (Fig. 1), Grazoprevir, and Boceprevir (HCV protease inhibitor) may be effective in binding to SARS-CoV-2 papain-like protease (PLpro) active sites to prevent viral replication (Table 5) (Elfiky and Ibrahim 2020). Regarding the lowest binding energy, the best ligand was found to be Telaprevir with a score of $-9.9 \mathrm{kcal} /$ mol. The results of docking analysis (Table 6) showed that Telaprevir forms hydrogen bonds with the $6 \mathrm{~W} 9 \mathrm{C}$ amino 
acids LYS B:92, HIS B:89 and THR A:74. In addition, there can be seen that the ligand interacts with LYS B: 92 via Pi-Cation and TYR A: 171 and ILE B: 44 via Pi-Alkyl interactions.

\section{Conclusions}

Our results show that the treatment of COVID-19 may potentially be addressed by repurposing existing, approved pharmaceutical drugs. In this virtual drug repurposing study based on docking analysis, using an established database for protein and ligand structures, we obtained the predicted binding scores of several drugs. This will be important in evaluating the findings of continuing clinical trials testing small molecule drugs for efficacy against SARS-CoV-2 and the drugs different mechanisms of action. Imatinib plays roles in cytoskeletal rearrangement, inflammatory signaling, NK and Regulatory T-cell modulation, and oxidant-induced epithelial cell injury followed by infection and ARDS which has been diagnosed among COVID-19 patients. Another TKI, Abivertinib, has an immunomodulatory function in patients with ARDS. In addition, Remdesivir, and Telaprevir have the most efficiency with their docked proteins in silico as well.

Funding Not applicable.

Availability of data and material The data supporting the findings of this study are available within the article.

\section{Declarations}

Ethics approval and consent to participate Not applicable.

Consent for publication Not applicable.

Conflict of interest The authors declare that they have no competing interests.

\section{References}

Arya R, Das A, Prashar V, Kumar M (2020) Potential inhibitors against papain-like protease of novel coronavirus (SARS-CoV-2) from FDA approved drugs. ChemRxiv. https://doi.org/10.26434/chemr xiv.11860011.v2

Caly L, Druce JD, Catton MG, Jans DA, Wagstaff KM (2020) The FDA-approved drug ivermectin inhibits the replication of SARSCoV-2 in vitro. Antivir Res 178:104787

Cao Y, Wei J, Zou L, Jiang T, Wang G, Chen L et al (2020) Ruxolitinib in treatment of severe coronavirus disease 2019 (COVID-19): a multicenter, single-blind, randomized controlled trial. J Allergy Clin Immunol 146(1):137-46.e3
Chen C, Zhang X, Ju Z, He W (2020) Advances in the research of cytokine storm mechanism induced by Corona Virus Disease 2019 and the corresponding immunotherapies. Chin J Burns 36:E005

Chen C, Huang J, Cheng Z, Wu J, Chen S, Zhang Y et al (2020) Favipiravir versus arbidol for COVID-19: a randomized clinical trial. medRxiv 2020.03.17.20037432

Choudhary S, Malik YS, Tomar S, Tomar S (2020) Identification of SARS-CoV-2 cell entry inhibitors by drug repurposing using in silico structure-based virtual screening approach. ChemRxiv 11:1664

Cavasotto C, Filippo JD (2020) In silico Drug Repurposing for COVID-19: Targeting SARS-CoV-2 Proteins through Docking and Quantum Mechanical Scoring. ChemRxiv. https://doi.org/10. 26434/chemrxiv.12110199.v2

Coleman CM, Sisk JM, Mingo RM, Nelson EA, White JM, Frieman MB (2016) Abelson kinase inhibitors are potent inhibitors of severe acute respiratory syndrome coronavirus and middle east respiratory syndrome coronavirus fusion. J Virol 90(19):8924-8933

DeBiasi RL, Song X, Delaney M, Bell M, Smith K, Pershad J et al (2020) Severe COVID-19 in children and young adults in the Washington, DC metropolitan region. J Pediatr 223:199-203

Di Lorenzo G, Di Trolio R, Kozlakidis Z, Busto G, Ingenito C, Buonerba L et al (2020) COVID 19 therapies and anti-cancer drugs: a systematic review of recent literature. Crit Rev Oncol Hematol 152:102991

Divya M, Vijayakumar S, Chen J, Vaseeharan B, Durán-Lara EF (2020) South Indian medicinal plants can combat deadly viruses along with COVID-19? A review. Microb Pathog 148:104277

Durdagi S, Aksoydan B, Dogan B, et al (2020) Screening of clinically approved and investigation drugs as potential inhibitors of SARS$\mathrm{CoV}-2$ main protease and spike receptor-binding domain bound with ACE2 COVID19 target proteins: a virtual drug repurposing study. ChemRxiv. https://doi.org/10.26434/chemrxiv.12032712.v2

Eastman RT, Roth JS, Brimacombe KR, Simeonov A, Shen M, Patnaik S, Hall MD (2020) Remdesivir: a review of its discovery and development leading to emergency use authorization for treatment of COVID-19. ACS Cent Sci 6(5):672-683. https://doi.org/10. 1021/acscentsci.0c00489

Elfiky A, Ibrahim NS (2020) Anti-SARS and anti-HCV drugs repurposing against the Papain-like protease of the newly emerged coronavirus (2019-nCoV). Preprint (Version 1). Research Square. https://doi.org/10.21203/rs.2.23280/v1

Elfiky AA, Ibrahim NS (2020) Anti-SARS and anti-HCV drugs repurposing against the papain-like protease of the newly emerged coronavirus (2019-nCoV)

Favalli EG, Biggioggero M, Maioli G, Caporali R (2020) Baricitinib for COVID-19: a suitable treatment? Lancet Infect Dis 20:1012-1013

Gordon CJ, Tchesnokov EP, Feng JY, Porter DP, Gotte M (2020) The antiviral compound remdesivir potently inhibits RNA-dependent RNA polymerase from Middle East respiratory syndrome coronavirus. J Biol Chem jbc.AC120:013056

Grein J, Ohmagari N, Shin D, Diaz G, Asperges E, Castagna A et al (2020) Compassionate use of remdesivir for patients with severe covid-19. N Engl J Med 382:2327-2336

Ibrahim IM, Abdelmalek DH, Elshahat ME, Elfiky AA (2020) COVID19 spike-host cell receptor GRP78 binding site prediction. J Infect 80(5):554-562

Jakovac H (2020) COVID-19: is the ACE2 just a foe? Am J Physiol Lung Cell Mol Physiol 318(5):L1025-L1026

Kerkelä R, Grazette L, Yacobi R, Iliescu C, Patten R, Beahm C et al (2006) Cardiotoxicity of the cancer therapeutic agent imatinib mesylate. Nat Med 12(8):908-916

Khatri A, Wang J, Pendergast AM (2016) Multifunctional Abl kinases in health and disease. J Cell Sci 129(1):9 
Koonin EV, Gorbalenya AE, Chumakov KM (1989) Tentative identification of RNA-dependent RNA polymerases of dsRNA viruses and their relationship to positive strand RNA viral polymerases. FEBS Lett 252(1-2):42-46

Mesa RA, Yasothan U, Kirkpatrick P (2012) Ruxolitinib. Nat Rev Drug Discov 11(2):103-104

Mulgaonkar N, Wang H, Mallawarachchi S, Fernando S, Martina B, Ruzek D (2020) Bcr-Abl tyrosine kinase inhibitor imatinib as a potential drug for COVID-19. bioRxiv 2020.06.18.158196

Pal R, Bhadada SK (2020) Should anti-diabetic medications be reconsidered amid COVID-19 pandemic? Diabetes Res Clin Pract. 163:108146. https://doi.org/10.1016/j.diabres.2020.108146.

Pesu M, Laurence A, Kishore N, Zwillich SH, Chan G, O'Shea JJ (2008) Therapeutic targeting of Janus kinases. Immunol Rev 223(1):132-142

Prompetchara E, Ketloy C, Palaga T (2020) Immune responses in COVID-19 and potential vaccines: lessons learned from SARS and MERS epidemic. Asian Pac J Allergy Immunol 38(1):1-9. https://doi.org/10.12932/ap-200220-0772.

Qin C, Zhou L, Hu Z, Zhang S, Yang S, Tao Y et al (2020) Dysregulation of immune response in patients with coronavirus 2019 (COVID-19) in Wuhan, China. Clin Infect Dis 71:762-768

Quartuccio L, Semerano L, Benucci M, Boissier M-C, De Vita S (2020) Urgent avenues in the treatment of COVID-19: targeting downstream inflammation to prevent catastrophic syndrome. Jt Bone Spine 87(3):191

Riviere P, Riviere M, Reader S (2012) Use of imatinib to treat liver disorders and viral infections. Google Patents

Rizzo AN, Aman J, van Nieuw Amerongen GP, Dudek SM (2015) Targeting Abl kinases to regulate vascular leak during sepsis and acute respiratory distress syndrome. Arterioscler Thromb Vasc Biol 35(5): 1071-1079

Shaw TD, McAuley DF, O'Kane CM (2019) Emerging drugs for treating the acute respiratory distress syndrome. Expert Opin Emerg Drugs 24(1):29-41

Sisk JM, Frieman MB, Machamer CE (2018) Coronavirus S proteininduced fusion is blocked prior to hemifusion by Abl kinase inhibitors. J Gen Virol 99(5):619

Sun M, Yang J, Sun Y, Su G (2020) Inhibitors of RAS might be a good choice for the therapy of COVID-19 pneumonia. Chin J Tuberc Respir Dis 43:E014
Talluri S (2020) Molecular Docking and Virtual Screening based prediction of drugs for COVID-19. Comb Chem High Throughput Screen 23:1. https://doi.org/10.2174/13862073236662008141 32149

Titanji BK, Farley MM, Mehta A, Connor-Schuler R, Moanna A, Cribbs SK, O'Shea J, DeSilva K, Chan B, Edwards A, Gavegnano C, Schinazi RF, Marconi VC (2021) Use of baricitinib in patients with moderate to severe coronavirus disease 2019. Clin Infect Dis 72(7):1247-1250. https://doi.org/10.1093/cid/ciaa879

Tools A (2016) 1.5. 6 (ADT)/MGL Tools 1.5. 6, The Scripps Research Institute, CA, USA, 2012

Trott O, Olson AJ (2010) AutoDock Vina: improving the speed and accuracy of docking with a new scoring function, efficient optimization, and multithreading. J Comput Chem 31(2):455-461

Wang M, Cao R, Zhang L, Yang X, Liu J, Xu M et al (2020a) Remdesivir and chloroquine effectively inhibit the recently emerged novel coronavirus (2019-nCoV) in vitro. Cell Res 30(3):269-271

Wang D, Guo J, Yang Z, You Y, Chen Z, Chen S, et al (2020)The first report of the prevalence of COVID-19 in Chronic myelogenous leukemia patients in the core epidemic area of China: multicentre, cross-sectional survey. medRxiv. https://doi.org/10.1101/2020.03. 12.20034876

World Health Organization (WHO) (2020) Coronavirus disease 2019 (COVID-19) situation report-45. https://www.who.int/docs/defau 1t-source/coronaviruse/situation-reports/20200305-sitrep-45covid-19.pdf

Yavuz S, Ünal S (2020) Antiviral treatment of COVID-19. Turk J Med Sci 50(SI-1):611-619

Zheng M, Gao Y, Wang G, Song G, Liu S, Sun D et al (2020) Functional exhaustion of antiviral lymphocytes in COVID-19 patients. Cell Mol Immunol 17:533-535

Zhou P, Yang X-L, Wang X-G, Hu B, Zhang L, Zhang W et al (2020) A pneumonia outbreak associated with a new coronavirus of probable bat origin. Nature 579(7798):270-273

Publisher's Note Springer Nature remains neutral with regard to jurisdictional claims in published maps and institutional affiliations. 